\title{
NULLIUS IN VERBA: SCIENCE VS PSEUDO-SCIENCE/FRINGE SCIENCE
}

\author{
Boris Aberšek \\ University of Maribor, Slovenia
}

The Royal Society's' motto 'Nullius in verba' is taken to mean 'take nobody's word for it'. It is an expression of the determination of Fellows to withstand the domination of authority and to verify all statements by an appeal to facts determined by experiment. Royal Society

The explosion of disinformation about global warming and other ecological problems could be called an infodemic ${ }^{2}$, which is the term used by WHO to describe today's pandemic situation. An infodemic means too much information, however, its importance can also be passed on to environmental problems. It causes confusion and risk-taking behaviors that can harm the health of our planet. It also leads to mistrust in authorities and undermines the public response. An infodemic can intensify or lengthen outbreaks when people are unsure about what they need to do, for example, to protect our environment. With growing digitization - an expansion of social media and internet use - information can spread more rapidly. This can help to more quickly fill information voids but can also amplify harmful messages.

Infodemic management is the systematic use of risk-and evidence-based analysis and approaches to manage the infodemic and reduce its impact on our environment. Infodemic management in relation to ecological problems focuses on enabling good practices through four types of activities:

- $\quad$ Listening to community concerns and questions.

- Promoting understanding of risk and health expert advice.

- Strengthening resilience to misinformation.

- Engaging and empowering communities to take positive action.

Infodemic management is widely known, but much less discussed is the role of ostensible "experts" or fringe scientists in perpetuating dangerous fictions. Since the dawn of the crisis, a disconcerting number of eminently qualified (pseudo)scientists and physicians have propagated falsehoods across social media, elevating themselves to the status of gurus in order to lend a veneer of seeming scientific legitimacy to empty, dangerous claims. And

1 https://royalsociety.org/about-us/history/

2 An infodemic is too much information including false or misleading information in digital and physical environments during a disease outbreak. See: https://www.who.int/health-topics/infodemic\#tab=tab_1 
these bogus claims, like their pathological namesake, have gone uncontrollably viral. These fringe pseudoscientists are lauded as experts unafraid to speak truth to power. But it is crucial to note that these individuals, for all their formal credentials, extol a narrative completely at odds with reality, readily refuted by public bodies the world over. These pseudoscientific, conspiratorial claims are archetypal arguments from authority, where a perceived expert's support is used to justify positions unsupported by data. Scientific claims do not derive their authority by virtue of coming from scientists but from the weight of the evidence behind them. Pseudoscience, by contrast, tends to focus on ostensible gurus (see Kanneman system 1) rather than a consensus opinion (see Kanneman system 2) (Kanneman, 2011). The only authority a scientist can ever truly invoke is a reflected one, dependent on accurately representing the evidence base. If they embrace fringe positions and jettison the principles of scientific skepticism, then their qualifications, education, and prestige mean absolutely nothing (Grimes, 2021).

In order to justify facts, scientists (unfortunately) use complex scientific methods, which are largely incomprehensible to most people. Meanwhile, pseudo-scientists use methods that are closer and more unambiguous to the everyman. Real science should be more approachable to the everyman, it should use such methods and arguments, which would be easier for people to understand, while at the same time not crossing the line of dismissing the accuracy and, above all, the reliability of what is being said, at the expense of improving intelligibility. If, while generalizing, we omit the less relevant and difficult-to-understand arguments and generalize to the level of the general population's understanding, then - as we reverse the generalization, adding more or less relevant data, which was omitted in the process of simplification - we should always be able to return to the starting point of the problem at hand, to the same complex scientific explanation.

In essence, the simplification process must be reversible, which means that a reverse process will bring us back to the starting point, which is symbolically shown in Figure 1.

\section{Figure 1}

The Simplification Principle (Aberšek, 2015, a,b)

\begin{tabular}{|c|c|c|c|c|}
\hline $\begin{array}{l}\text { Science-based } \\
\text { representation }\end{array}$ & $\begin{array}{l}\text { Simplification } \\
1\end{array}$ & $\rightarrow{ }_{2}^{\text {Simplification }}$ & $\rightarrow \begin{array}{l}\text { Simplification } \\
3\end{array}$ & $\begin{array}{l}\text { Simplified } \\
\text { representation }\end{array}$ \\
\hline & $\begin{array}{l}\text { Abolishment } \\
\text { of } \\
\text { simplification } \\
1\end{array}$ & $\begin{array}{l}\text { Abolishment } \\
\text { of } \\
\text { simplification } \\
2\end{array}$ & $\begin{array}{l}\text { Abolishment } \\
\text { of } \\
\text { simplification } \\
3\end{array}$ & \\
\hline
\end{tabular}

\section{The Difference between COVID-19 and Environmental Problems}

Though people live in the here-and-now, they have the capacity to think about future events, remote places, distant others, and alternative realities. This ability to think about events that extend beyond the immediate context is one that many might take for granted. Construal level theory $(C L T)$ attempts to explain how people accomplish this remarkable feat. Central to understanding CLT is the idea of psychological distance (Trope \& Liberman, 2010). Construal level theory $(C L T)$ is a theory in social psychology that describes the relationship between psychological distance and the extent to which people's thinking (e.g., about objects and events) is abstract or concrete. The general idea is that the more distant an object is from the individual, the more abstract it will be thought of, while the closer the object is, the more concretely it will be thought of.

Let us provide a topical example of a low level construal, i.e., when people think more about the context-specific features: COVID-19. We are all aware that we will have to find a solution as soon as possible, and the only currently logical solution is vaccination. With this in mind, scientists have joined forces and developed a vaccine in less than a year's time. The process of vaccine development and adoption, which in recent history took considerably longer, several years, now took less than a year. This solution, which may be more or less optimal, reliable and hazardous, 
has withstood the anti-vaccine sentiment of numerous and various groups, and the vast majority of people have decided to get vaccinated, which makes perfect sense, considering the state of chaos in which we currently are.

High level construal means that the more distant an object is from the individual, the more abstractly it will be thought of. With long-term abstract thinking, many of the things we are aware of fall away, we negate time, we are not ready to make compromises, we doubt the proposed solutions, or even deny the existence of a problem (for example, environmental issues), and there is always the question of whom we can trust. The foundation of trust is based upon the realization that various "non-scientists and pseudo-scientists" are exploiting science for their own purposes, thereby destroying trust in science. The rise of pseudo-experts is perhaps symptomatic of a change in how we access information. As we become curators of our own media, the traditional gatekeepers and fact-checkers once implicit in most reporting have been increasingly sidelined. This in turn has made us more polarized and reduced our ability to differentiate fact from opinion. Motivated reasoning ${ }^{3}$, our human bias towards cherry-picking only arguments that chime with that we wish were true, most certainly plays a role. The impositions of global warming and other ecological problems are manifold; it is not surprising that fringe scientists are inevitably invoked as sources for those with strong feelings against, for example, measures to reduce greenhouse emissions. Even if we are not ideologically predisposed to such positions, these claims undermine public understanding, blurring perceptions of scientific consensus, nudging us collectively towards fear and distrust.

Understanding the process of science can protect people against misinformation - or at least we hope so. One of the most intriguing stages in the process of science is noticing when something is ... weird. 2020 has been a historic year - and mostly not in a good way. Among many things, we saw a historic level of disregard of scientific advice with respect to the COVID-19 virus. But while the events of 2020 may feel unprecedented, the social pattern of rejecting scientific evidence did not suddenly appear this year. There was never any good scientific reason for rejecting the expert advice on COVID, just as there has never been any good scientific reason for doubting that humans evolved, that vaccines save lives, and that greenhouse gases are driving disruptive climate change.

For all their qualifications, fringe scientists fail this basic tenet of science, as they are united in their willingness to embrace conspiracy theory when their claims are refuted. Lack of evidence for their position is airily dismissed as a cover-up by everyone from authorities at a global level, to the entire ecological establishment. But this performative outrage is so much sound and fury to distract from the inescapable reality that their positions are completely contradicted by the overwhelming weight of scientific evidence. This is scientifically reprehensible, and staggeringly irresponsible, conduct.

\section{Potential Solutions}

In recent decades, the gap between scientists, pseudo-scientists, influencers, and politicians has become increasingly clear. The question of whom one can trust, whom one can believe, is becoming ever more common. The solutions to this problem need to be long-term and systematic and developed especially by means of:

- developing critical thinking and critical decision-making of the whole society (or at least a large part of it, as true believers can never be convinced by the power of arguments),

- facts (logical argumentation, good science) versus pseudo-facts (bad science) arising from the problem of interpretation (System 1 or System 2),

- a strategic separation of truth from potential lies (unverified or poorly verified facts) or actual lies (deception and manipulation), which are a result of using pseudo-scientific methods and misleading use of various statistical explanations and shortcuts.

It is entirely understandable that many are left confused and uneasy by the vocal assertions of fringe figures, but the onus of proof is always on those making grand claims. The history of science is littered with the hubris of the arrogant and misguided, and mere credentials are no impediment to being wrong; only evidence truly matters. When confronted with the pronouncement of fringe figures, the motto of the Royal Society should always be at the forefront of our mind: Nullius in Verba (take nobody's word for it) (Grimes, 2021).

\footnotetext{
3 Motivated reasoning is a phenomenon studied in cognitive science and social psychology that uses emotionally biased reasoning to produce justifications or make decisions that are most desired rather than those that accurately reflect the evidence, while still reducing cognitive dissonance.
} 


\section{References}

Aberšek, B. (2015a). Elegance in science and science education. Journal of Baltic Science Education, 14(4), 420-423. http://www.scientiasocialis.lt/jbse/?q=node/442

Aberšek, B. (2015b). Changing educational theory and practice. Problems of Education in the 21st Century, 66, 4-6. https://dx.doi.org/10.33225/pec/15.66.04

Grimes, D. R. (2021). COVID has created a perfect storm for fringe science. Scientific American, April. https://www.scientificamerican.com/article/covid-has-created-a-perfect-storm-for-fringe-science/

Kanneman, D. (2011). Thinking, fast and slow. Farrar, Straus and Giroux. https://psycnet.apa.org/record/2011-26535-000

Trope, Y., \& Liberman, N. (2010). Construal-level theory of psychological distance. Psychological Review, 117(2), 440-463. https://doi.org/10.1037/a0018963 